\title{
An epidemiological approach to study fatigue in the working population: the Maastricht Cohort Study
}

\section{IJ Kant, U Bültmann, K A P Schröer, A J H M Beurskens, L G P M van Amelsvoort, G M H Swaen}

See end of article for

authors' affiliations

Occup Environ Med 2003;60(Suppl I):i32-i39

Correspondence to: Dr IJ Kant, Department of Epidemiology, Maastricht University, PO Box 616,

6200 MD Maastricht,

Netherlands;

JJ.Kant@epid.unimaas.nl

Accepted

7 November 2002
In 1998, a large scale prospective cohort study of prolonged fatigue in the working population was started in the Netherlands. The ultimate goal of this Maastricht Cohort Study was to identify risk factors involved in the aetiology and natural course of prolonged fatigue in the working population and to develop preventive measures and treatments that can be used in occupational health settings. In this paper, a conceptual model for epidemiological research on prolonged fatigue is presented. This model is the basis for the Maastricht Cohort Study. Alongside the model and design, the characteristics of the study population, the prevalence and one year cumulative incidence of prolonged fatigue, as well as its relation with secondary health outcomes (psychological distress, need for recovery, and burnout) are presented. Furthermore, model, design, and the presented results are discussed.
$\mathrm{F}$ atigue in the working population has attracted renewed attention in occupational (mental) health research, ${ }^{12}$ since it may affect the individual's performance and ability to function in the occupational and home settings, and may lead to sick leave and (work) disability. ${ }^{3}$ In the Netherlands, about one in every three work disability benefit recipients is classified as disabled for work on mental grounds. ${ }^{4}$ It is generally assumed that prolonged fatigue is a major symptom in this kind of work disability. The increasing awareness of the impact of prolonged fatigue on the individual employee, the employer, and society has led to the recognition that there is need for valid information about the magnitude of fatigue in the working population and about the risk factors involved in the aetiology of fatigue. The absence of these data and the need for preventive measures has prompted the establishment of a large scale epidemiological Maastricht Cohort Study on "Fatigue at Work".

In 1998, as part of the Netherlands' concerted research action, the Maastricht Cohort Study (MCS) was set up: (1) to examine the prevalence and incidence of prolonged fatigue in the working population; (2) to identify risk factors involved in the onset and natural course of prolonged fatigue in the working population; and (3) to investigate the effectiveness of different treatments for fatigue. Within the MCS different research projects are carried out. The ultimate objective of the MCS is to develop preventive measures and actions for fatigue that can be used in occupational settings.

Unfortunately, the definition and assessment of fatigue have been subjects of controversy for many years. ${ }^{5-8}$ Discussion points include whether fatigue is a discrete entity (chronic fatigue syndrome, myalgic encephalomyelitis), a set of symptoms of unknown origin, or a specific form of psychological disturbance. We do know, however, that fatigue is a common complaint, ${ }^{9-15}$ which is best seen as a subjective sensation with behavioural, emotional, and cognitive components. ${ }^{5}$ In a review on the epidemiology of fatigue in both the community and primary care settings, Lewis and Wessely ${ }^{5}$ reported preva-

\section{Main messages}

- A conceptual model for epidemiological research of prolonged fatigue in the working population is presented.

- Prolonged fatigue is common in the working population (prevalence $21.9 \%$ ).

- Prolonged fatigue is associated with psychological distress, need for recovery, and burnout. lence rates varying from $7 \%$ to $45 \%$. Although different definitions and measurements of fatigue, different settings and response rates, as well as different duration criteria for fatigue hinder a direct comparison, the prevalence of fatigue was $14.3 \%$ in men and $20.4 \%$ in women in the US Health and Nutrition Examination Survey, ${ }^{9} 22 \%$ (11\% for six months or longer) in the general Norwegian population, ${ }^{15} 25 \%$ (at least two weeks duration) in an Australian primary care study, ${ }^{14}$ and $38 \%$ ( $18 \%$ for six months or longer) in a UK community survey. ${ }^{12}$ Several studies conducted in the community and in primary care settings have shown that fatigue is continuously distributed, with some degree of fatigue in nearly all of the population. ${ }^{10}{ }^{15}$ Hence, fatigue as a concept is best viewed as a continuum.

Even though an extensive body of literature on this complex subject has been helpful in advancing the understanding of the concept of fatigue, some issues remain largely unresolved. For example, what is the relation between the mild, frequent complaints of fatigue seen in the community and the severe, disabling fatigue characteristics of chronic fatigue syndrome? ${ }^{5}$ While fatigue that occurs as a normal, everyday phenomenon is usually relieved by a period of rest, prolonged fatigue is not easily reversible in the short term, ${ }^{216}$ and may accompany physical illnesses and psychiatric disorders. $^{911} 1214151718$

This prolonged fatigue may affect the individual performance. Within the working population fatigue may also affect the ability to function in the occupational setting and may lead to sick leave and work disability. ${ }^{19}$ For the development of measures to prevent sick leave and work disability because of fatigue, it is important to identify the risk factors for the onset and natural course of fatigue. In the literature, the likely multifactorial aetiology of fatigue is emphasised, ${ }^{6}$ and "psychosocial" reasons (for example, work, family, and lifestyle) are

\section{Policy implications}

- In order to examine the aetiology and natural course of prolonged fatigue in the working population, a longitudinal approach, including a variety of factors and frequent measurements during follow up are required.

Abbreviations: $\mathrm{CIS}$, Checklist Individual Strength; $\mathrm{GHQ}$, General Health Questionnaire; MBI-GS, Maslach Burnout Inventory-General Survey; MCS, Maastricht Cohort Study 


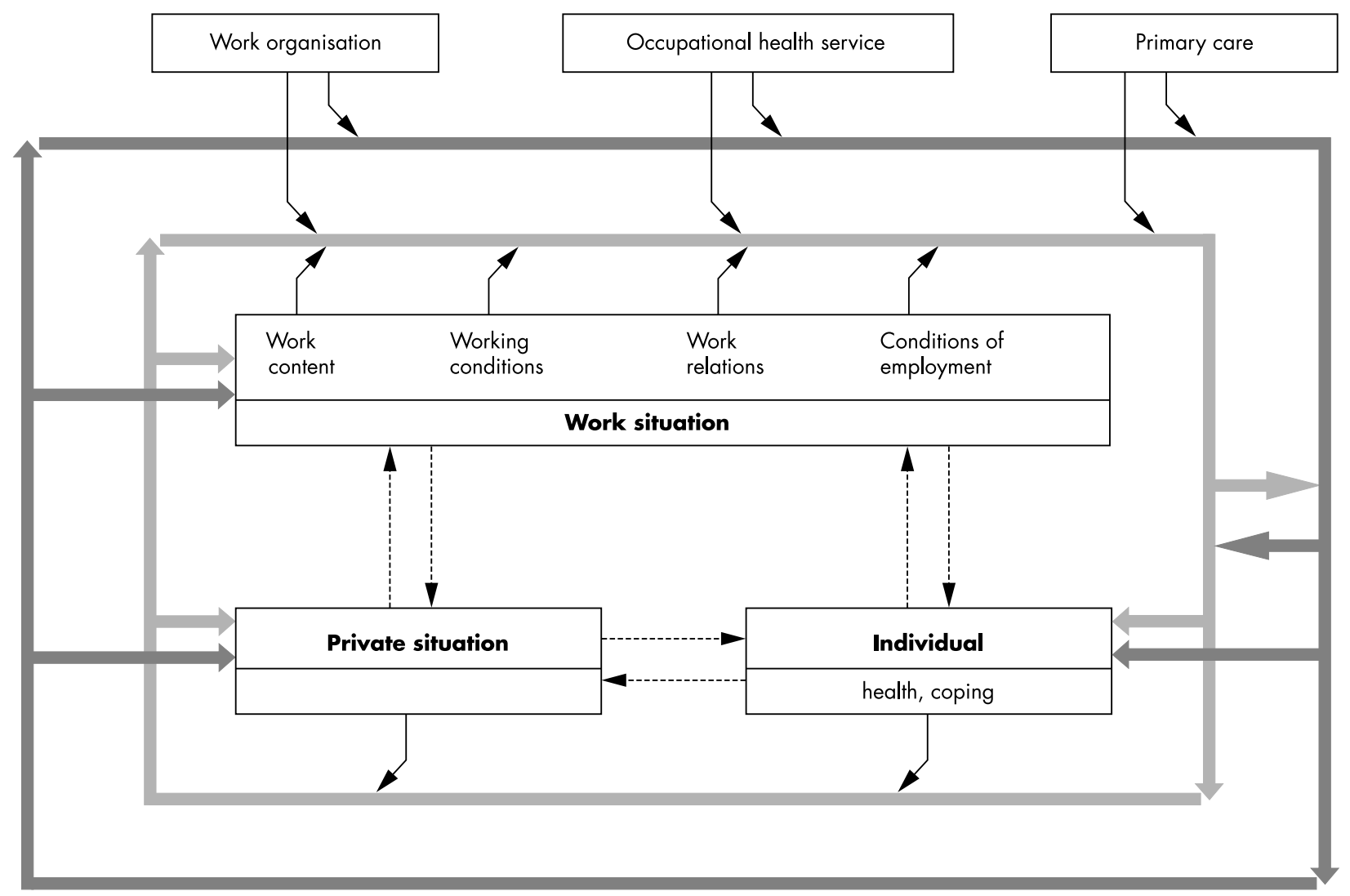

$$
\begin{aligned}
& =\text { Fatigue } \\
& =\text { Consequences of fatigue (sick leave, work disability) }
\end{aligned}
$$

Figure 1 Conceptual model for epidemiological research on fatigue in the working population.

most often mentioned as explanations for feeling fatigued. ${ }^{7}$ However, there is very little information about risk factors which predict fatigue in the working population. With regard to the working population, Hardy and colleagues ${ }^{17}$ reported in a cross sectional study using specific occupational groups in the workforce of the UK National Health Service Trusts, that high work demands and role conflict were related to high levels of fatigue. Another cross sectional study among Israeli industrial employees revealed that "not being active during leisure time" and smoking 10 or more cigarettes per day were associated with more complaints of severe fatigue. ${ }^{20}$ Besides work and lifestyle factors, other factors such as individual characteristics (for example, health status and coping), ${ }^{21}{ }^{22}$ and domestic and social factors (for example, demands in home life $)^{23}$ may be involved in the onset of fatigue in the working population. Given the cross sectional nature of most previous studies, it is important to note that an interpretation concerning cause and effect is doubtful.

In the present paper, we present an epidemiological approach to study of prolonged fatigue in the working population. In the first part of the paper, theoretical and conceptual considerations are addressed and translated into a conceptual model for epidemiological research on fatigue in the working population. The design of the Maastricht Cohort Study is based on this model. The second part of the paper focuses on prolonged fatigue, the main outcome measure of the Maastricht Cohort Study. The distribution of prolonged fatigue, the prevalence across different levels-that is, sectors and trades, companies, departments at baseline, the one year cumulative incidence, and associations with secondary health outcomes, are presented and discussed.

\section{TOWARDS A CONCEPTUAL MODEL FOR EPIDEMIOLOGICAL RESEARCH ON FATIGUE IN THE WORKING POPULATION}

To determine the risk factors in the aetiology and natural course of prolonged fatigue a conceptual model for epidemiological research on fatigue in the working population was developed. The model incorporates the current concept of fatigue and takes into account the consequences of fatigue, the multifactorial aetiology of fatigue, and the complex relations/interactions between risk factors and fatigue and the consequences of fatigue. Figure 1 shows the conceptual model. Fatigue is viewed as a continuum, ranging from mild, frequent complaints to severe, disabling fatigue characteristics, and is represented by the bold grey inner line. As stated earlier, fatigue may affect the individual's performance and functioning and may lead to consequences such as sick leave or work disability. The consequences of fatigue are presented by the bold black outer line (fig 1).

In the working population, various factors in the work environment (for example, work content, working conditions) may play a role in the onset of fatigue. Besides work related factors, the private situation (domestic and social factors) and individual characteristics (for example, health status, lifestyle, and coping) may be involved in the aetiology of fatigue. These exposure domains, comprising a broad range of potential risk 


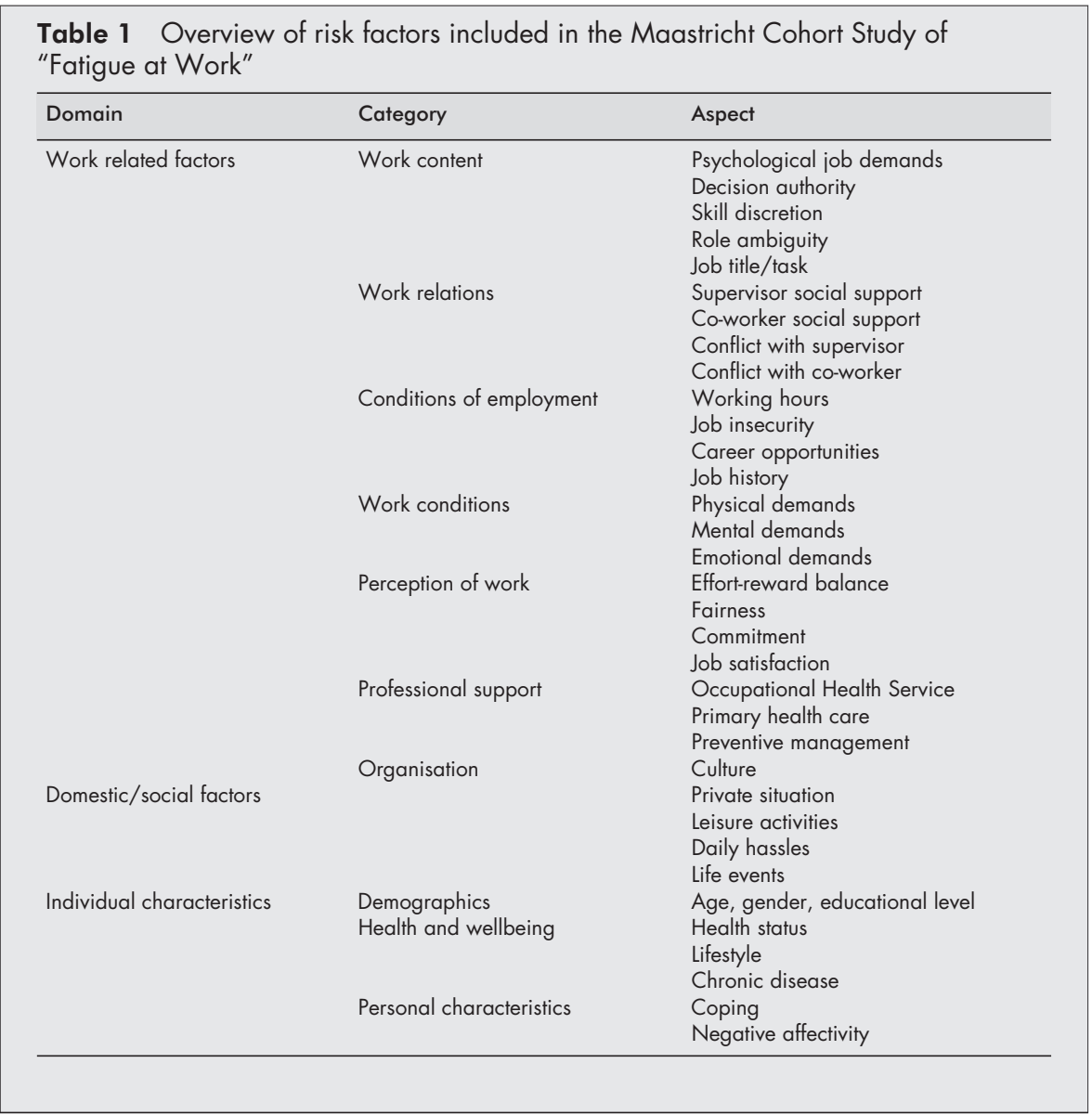

factors, are presented by three boxes in the middle of the model. Each of the factors may separately or in combination with other factors act as a risk factor for prolonged fatigue. Moreover, it is likely that interactions exist between the three exposure domains; for example, the interaction between work and family life ${ }^{24} 25$ (see dotted arrows in fig 1). Fatigue may lead to sick leave and work disability. These consequences of fatigue are influenced by the level of fatigue, which is determined by the risk factors described above. In addition, the aetiology and natural course of fatigue may be influenced by the work organisation (for example, company's working conditions policy), the occupational health service (for example, consultation), and primary health care (for example, consultation/treatment). Both fatigue and the consequences of fatigue may influence the exposure variables, which may lead to feedback mechanisms including reverse causation (see bold black and grey arrows in fig 1).

In order to examine causal relations, a longitudinal approach is required because the sequence of observations corresponds with the natural course of the event and the exposures are measured before adverse health effects occur. Moreover, to examine causal relations, both exposure and outcome should be assessed on an individual level. ${ }^{26}$ It should be kept in mind that different exposure variables may follow different courses of effect. ${ }^{27}{ }^{28}$ The literature on long term health effects implicitly presumes a certain exposure time effect: the longer a stressor impacts on a person and/or the higher the exposure intensity, the higher the incidence of health effects. Depending on the type of stressor, the time-response curve may differ. ${ }^{27}$ The initial impact concept assumes a direct effect when a worker is exposed to a new stressor because of the unexpected nature of the new stressor and because useful coping strategies have not been developed ${ }^{29}$ In order to investigate the aetiology and natural course of fatigue in the work- ing population, both concepts may be relevant. The initial impact concept may be relevant when tasks or work schedules change and in case of life events, while the exposure time concept may be relevant for the majority of other risk factors. However, incorporating both concepts has implications for the sampling frequency. This means that for the initial impact concept the measurement points are at most a few months apart, whereas for the exposure time concept one or two years between the (onset) of stressors and the appearance of the effect is the relevant time frame. ${ }^{27}$ Based on these methodological considerations and the conceptual model described above, the Maastricht Cohort Study was designed.

\section{THE MAASTRICHT COHORT STUDY OF "FATIGUE AT WORK" \\ General outline}

The Maastricht Cohort Study (MCS) was set up as a prospective cohort study. During a three year follow up period, the MCS surveys a large heterogeneous population of employees from different companies and organisations. A broad range of exposure variables and fatigue are measured yearly on an individual level by means of self administered questionnaires. Moreover, follow up data on fatigue were obtained every four months by a short, mailed questionnaire. Additional data on sick leave and work disability are gathered by record linkages to company sick leave and work disability registry systems; data on organisational characteristics are obtained by questionnaire and by interviews with a company's personnel manager.

\section{Study population}

In order to investigate the wide variety of risk factors and to ensure contrast in the different exposure variables, a large 
heterogeneous occupational study population was required. It was calculated that the size of the study population during follow up had to be approximately 10000 employees. Employees with different jobs and educational levels from various companies and organisations, representing different sectors and trades, were approached to participate in the study. Included were men and women, aged 18-65 years, with a minimum employment of 16 hours/week. Temporary workers were excluded from the study because they (may) change jobs frequently and because accurate data on sick leave and work disability were difficult to obtain.

\section{Exposure variables}

Table 1 presents an overview of the potential risk factors for fatigue included in the Maastricht Cohort Study. Three domains of exposure, comprising a wide variety of work related factors, domestic and social factors, as well as individual characteristics, were measured. The majority of the risk factors were assessed with existing, validated questionnaires (detailed information about the used questionnaires, scales, and items is available on request).

\section{Outcome measures}

In the Maastricht Cohort Study, the main outcome measures are prolonged fatigue and the consequences of fatigue in terms of sick leave and work disability. Alongside these main outcomes, several secondary health outcomes were measured: (a) psychological distress, since various studies have shown that fatigue is associated with psychological distress ${ }^{12} 14$ 17 30-32; (b) need for recovery (or unwinding), since it may play a mediating or moderating role in the aetiology of prolonged fatigue; and (c) burnout, since fatigue is a predominant mood symptom of the burnout syndrome. ${ }^{33}$

\section{Main outcome measure}

Prolonged fatigue was measured with the 20 item self reported Checklist Individual Strength (CIS), which was originally developed for hospital studies of chronic fatigue syndrome. ${ }^{34}{ }^{35}$ The CIS covers several aspects of fatigue, such as severity (eight items), concentration (five items), motivation (four items), and physical activity level (three items). The CIS was thoroughly tested in the clinical setting. ${ }^{35}{ }^{36}$ Before the establishment of the Maastricht Cohort Study, a pilot study was conducted to validate the CIS in the working population by means of defined samples with differences in fatigue level. From this pilot study, it was concluded that the CIS was able to differentiate between the samples with different fatigue levels. ${ }^{37}$ Employees are instructed to indicate how they felt during the previous two weeks. The response to each item is scored on a seven point Likert scale. Higher scores indicate a higher degree of fatigue, more concentration problems, reduced motivation, or less activity. These components fit in with our concept of fatigue. Therefore, within the Maastricht Cohort Study the CIS total score, comprising all subscales, was used. To generate a CIS total score, the responses to the individual items were summed up (range 20-140). A cut off point for case classification was established in the above mentioned pilot study. ${ }^{38}$ In the MCS, all employees scoring CIS total >76 were designated as fatigue cases.

\section{Secondary outcomes}

Psychological distress was assessed with a Dutch version of the 12 item General Health Questionnaire (GHQ-12). ${ }^{30}$ The GHQ-12 was developed as a screening instrument for detecting minor psychiatric disorders in the general population. Two scoring systems were used for the four point response scale. The Likert scoring method $(0,1,2,3)$ summed the responses of the 12 items to give a continuous distribution of the scores, ranging from 0 to 36 . The traditional GHQ scoring method $(0$, $0,1,1)$ is designed to identify individuals reporting sufficient
Table 2 Measurement of exposure variables and health outcomes in the Maastricht Cohort Study of "Fatigue at Work"

\begin{tabular}{|c|c|c|c|}
\hline Time & Questionnaire & $\begin{array}{l}\text { Exposure } \\
\text { measurement }\end{array}$ & $\begin{array}{l}\text { Outcome } \\
\text { measurement }\end{array}$ \\
\hline May 1998 (baseline) & Extensive & - & - \\
\hline September 1998 & Short & & - \\
\hline January 1999 & Short & & - \\
\hline May 1999 & Extensive & - & - \\
\hline September 1999 & Short & & - \\
\hline January 2000 & Short & & $\bullet$ \\
\hline May 2000 & Extensive & - & • \\
\hline September 2000 & Short & & • \\
\hline January 2001 & Short & & $\bullet$ \\
\hline
\end{tabular}

psychological distress to be classified as probable cases of minor psychiatric disorder. Given the possible range of scores from 0 to 12, the threshold for case classification in the MCS was 4 or higher. That means, all employees scoring four or more of the 12 items were considered to represent probable cases of psychological distress. The threshold for case classification is high but identical to the threshold used in previous workplace studies. ${ }^{1741}$

Need for Recovery was measured with a scale from a Dutch questionnaire on the Perception and Judgment of Work (VBBA). ${ }^{42}{ }^{43}$ The scale comprises 11 dichotomous items, representing short term effects of a day of work, for example, "it is difficult for me to relax at the end of a workday". The responses to the 11 items were summed up to generate a total score ranging from 0 to 100 . Higher scores indicate more complaints-that is, a higher need for recovery. Since no cut off point for case classification exists, in the MCS the highest quartile was used to define cases - that is, employees with a high need for recovery.

Burnout was assessed with the Dutch version of the Maslach Burnout Inventory-General Survey (MBI-GS)..33 44 The MBI-GS consists of three subscales: exhaustion (five items), cynicism (five items), and professional efficacy (five items). All items are scored on a seven point frequency scale, ranging from 0 (never) to 6 (daily). High scores on exhaustion and cynicism, and low scores on professional efficacy are indicative for burnout. Employees scoring in the highest quartile of exhaustion and in either the highest quartile of cynicism or the lowest quartile of professional efficacy were classified as burnout cases.

\section{Assessment of exposure and outcome}

During the three year follow up period from May 1998 to January 2001, data on demographics, work related factors, domestic and social factors, individual characteristics, fatigue, secondary health outcomes, as well as on self reported sick leave, were obtained yearly by means of an extensive, mailed self administered questionnaire. In addition to the yearly collection, follow up data on fatigue were gathered twice a year by a short, mailed self administered questionnaire. Overall, nine questionnaires had to be completed by the study participants (see table 2).

Additional data on organisational characteristics were gathered by questionnaire and by interviews with the company's personnel manager. Data on sick leave and work disability were obtained by record linkages to company sick leave and work disability registry systems. Moreover, detailed information about the natural course of prolonged fatigue, social-medical counselling, and treatment was gathered by telephone interviews every two months in a subsample of employees being on sick leave for at least six weeks. 


\section{PROLONGED FATIGUE: PREVALENCE, INCIDENCE, AND RELATION WITH SECONDARY HEALTH OUTCOMES}

To determine the prevalence and the one year cumulative incidence of prolonged fatigue and to examine the relation between prolonged fatigue and secondary health outcomes, data at baseline and after one year follow up were used.

\section{Study population at baseline and one year follow up}

In May 1998, 26978 employees from 45 Dutch companies and organisations received an introductory letter at home inviting participation and the baseline questionnaire. The letter explained the purpose and the general outline of the cohort study, described how the data would be used, and guaranteed anonymity of responses. The voluntary nature of participation was emphasised. Non-respondents received a written reminder two weeks later. After six weeks, a random sample of 600 persistent non-respondents was asked to complete a brief questionnaire about the reasons for non-response. In a non-response analysis, no significant differences were found between respondents and non-respondents on demographic characteristics. Non-respondents were less likely to report fatigue complaints ( $\left.42 \% v 55 \%, \chi^{2}=11.1, \mathrm{p}<0.05\right)$, sickness absence $\left(21 \% \vee 39 \%, \chi^{2}=21.5, \mathrm{p}<0.05\right)$, and difficulties in work execution because of health complaints (17\% v26\%, $\left.\chi^{2}=7.75, \mathrm{p}<0.05\right)$.

A total of 12161 employees completed and returned the baseline questionnaire. The overall response rate was $45 \%$. Written informed consent, including the use of sick leave data, was obtained from all participants. Twenty one questionnaires were excluded from the analysis for technical reasons. The baseline study population consisted of 12140 employees (73\% men and 27\% women), including 687 occupations and job titles.

In May 1999, those employees $(\mathrm{n}=11$ 272) who had completed the baseline questionnaire and at least one of the two short questionnaires were approached again to complete the extensive one year follow up questionnaire. A total of 9625 employees, 7025 men (73\%) and 2600 women (27\%), completed and returned the one year follow up questionnaire (response rate $80 \%$ ). A non-response analysis revealed that non-respondents during the first year of follow up were likely to report more fatigue complaints at baseline than respondents $\left(58 \% \vee 54 \%, \chi^{2}=10.8 \mathrm{p}<0.01\right)$ and were more often fatigue cases as measured with the CIS $(23.7 \% \vee 21.4 \%$, $\left.\chi^{2}=5.7, p<0.05\right)$. Furthermore, differences were found with regard to demographic and health factors. Non-respondents during the first year follow up were younger (38.9 v $41.5 \mathrm{y}$, $\left.\chi^{2}=172, \mathrm{p}<0.0001\right)$ and had a lower educational level (24.2\% low, $47.0 \%$ medium, $28.8 \%$ high $v 19.1 \%$ low, $45.1 \%$ medium, $35.8 \%$ high, $\left.\chi^{2}=53.5, \mathrm{p}<0.0001\right)$ than respondents. No significant difference was observed with respect to gender. Non-respondents during the first year of follow up reported higher sickness absence $\left(41.8 \%\right.$ v 38.4\%, $\chi^{2}=9.7$, $\mathrm{p}<0.005)$ and more difficulties in work execution because of health complaints $\left(28.7 \% v 24.6 \%, \chi^{2}=16.9, \mathrm{p}<0.0001\right)$.

\section{Data analysis}

The continuous scoring of the CIS, need for recovery, MBI-GS, and GHQ-12 (Likert scoring) at baseline were used: (a) to determine the distribution of fatigue, need for recovery, burnout, and psychological distress; and (b) to calculate the Pearson intercorrelations as well as the Cronbach's alpha for internal consistency. Then, the simple dichotomy of "non-case" and probable "case" was used to determine the prevalence at baseline and the cumulative one year incidence of fatigue, need for recovery, burnout, and psychological distress. The significance level for all statistical tests was fixed at 0.01. Data were analysed using SPSS 9.0.
Table 3 Characteristics of the study population $(n=12140)$ of the Maastricht Cohort Study at baseline

\begin{tabular}{|c|c|}
\hline Domain and aspect & $\%$ \\
\hline \multicolumn{2}{|l|}{ Individual characteristics } \\
\hline \multicolumn{2}{|l|}{ Gender } \\
\hline Men & 73.1 \\
\hline Women & 26.9 \\
\hline \multicolumn{2}{|l|}{ Age (y) } \\
\hline $18-25$ & 4.0 \\
\hline $26-35$ & 25.2 \\
\hline $36-45$ & 37.5 \\
\hline $46-55$ & 29.0 \\
\hline $56-65$ & 4.3 \\
\hline \multicolumn{2}{|l|}{ Highest educational level } \\
\hline Primary school & 4.4 \\
\hline Lower vocational school & 15.7 \\
\hline Lower secondary school & 13.0 \\
\hline Intermediate vocational school & 23.9 \\
\hline Secondary school & 8.6 \\
\hline Higher vocational school & 23.1 \\
\hline University & 11.3 \\
\hline \multicolumn{2}{|l|}{ Chronic disease } \\
\hline No & 75.8 \\
\hline Yes & 24.2 \\
\hline \multicolumn{2}{|l|}{ Domestic and social factors } \\
\hline \multicolumn{2}{|l|}{ Living situation } \\
\hline Alone & 10.2 \\
\hline Together with partner & 85.6 \\
\hline Together with parents & 4.2 \\
\hline \multicolumn{2}{|l|}{ Care for children } \\
\hline No & 46.1 \\
\hline Yes & 53.9 \\
\hline \multicolumn{2}{|l|}{ Work related factors } \\
\hline \multicolumn{2}{|l|}{ Working hours/week (excl. overtime) } \\
\hline$>40$ & 20.1 \\
\hline $36-40$ & 53.5 \\
\hline $26-35$ & 14.7 \\
\hline $16-25$ & 10.0 \\
\hline$<16$ & 1.7 \\
\hline \multicolumn{2}{|l|}{ Function } \\
\hline Executive & 24.1 \\
\hline Non-executive & 75.9 \\
\hline
\end{tabular}

\section{RESULTS}

\section{Characteristics of the study population at baseline}

Table 3 presents some selected characteristics of the study population at baseline. Overall, the study population is heterogeneous with respect to demographics, health status, domestic and social factors, and work related factors.

Distributions and associations of prolonged fatigue and secondary outcomes at baseline

Table 4 shows the means, standard deviations, and percentile scores of the outcome measures for the total population at baseline. The CIS score and the secondary health outcome scores had a continuous distribution with no cut off or rarity. The internal consistency of the measures was satisfactorythat is, Cronbach's alpha $>0.76$ (table 5). As presented in table 5 , the scores on the main outcome measure fatigue are fairly well correlated with the secondary outcomes. A high correlation was found between the scores on the CIS and the MBI-GS subscale exhaustion $(r=0.70)$. Moreover, the CIS was fairly well associated with the GHQ-12 and need for recovery, expressed by correlations of 0.62 and 0.63 respectively. Moderate correlations were observed between the secondary outcomes.

\section{Prevalence at baseline and one year cumulative incidence}

As table 6 illustrates, differences were found with respect to the prevalence and one year cumulative incidence between the outcome variables. As reported earlier, the prevalence of 
Table 4 Distribution (means, standard deviations, percentile scores) of prolonged fatigue and secondary health outcomes at baseline

\begin{tabular}{|c|c|c|c|c|c|c|c|c|}
\hline \multirow[b]{2}{*}{ Outcome measure (range) } & \multirow[b]{2}{*}{$\mathrm{n}$} & \multirow[b]{2}{*}{ Mean } & \multirow[b]{2}{*}{ SD } & \multicolumn{5}{|c|}{ Percentiles scores } \\
\hline & & & & 5 & 25 & 50 & 75 & 95 \\
\hline CIS (20-140) & 11902 & 57.2 & 23.7 & 24.0 & 38.0 & 54.0 & 74.0 & 99.8 \\
\hline Need for recovery $(0-100)$ & 12059 & 38.11 & 26.9 & 9.1 & 9.1 & 36.4 & 63.6 & 90.0 \\
\hline \multicolumn{9}{|l|}{ MBI-GS } \\
\hline Exhaustion (0-5) & 12084 & 1.85 & 1.17 & 0.20 & 1.00 & 1.60 & 2.40 & 4.20 \\
\hline Cynicism (0-4) & 12059 & 1.54 & 1.11 & 0.00 & 0.75 & 1.50 & 2.25 & 3.75 \\
\hline Professional efficacy (0-6) & 12072 & 4.07 & 0.96 & 2.33 & 3.50 & 4.16 & 4.83 & 5.50 \\
\hline GHQ-12 (0-36) & 12025 & 11.61 & 5.36 & 6.00 & 8.00 & 10.00 & 14.00 & 23.00 \\
\hline
\end{tabular}

Table 5 Correlation matrix of the outcome measures and Cronbach's alphas (in bold) within the Maastricht Cohort Study

\begin{tabular}{|c|c|c|c|c|c|c|}
\hline & \multirow[b]{2}{*}{ CIS } & \multirow[b]{2}{*}{$\begin{array}{l}\text { Need for } \\
\text { recovery }\end{array}$} & \multicolumn{3}{|l|}{ MBI-GS } & \multirow[b]{2}{*}{ GHQ-12 } \\
\hline & & & Exhaustion & Cynicism & $\begin{array}{l}\text { Professional } \\
\text { efficacy }\end{array}$ & \\
\hline $\mathrm{CIS}$ & $(0.93)$ & & & & & \\
\hline $\begin{array}{l}\text { Need for recovery } \\
\text { MBI-GS }\end{array}$ & 0.633 & $(0.78)$ & & & & \\
\hline Exhaustion & 0.695 & 0.734 & $(0.88)$ & & & \\
\hline Cynicism & 0.468 & 0.373 & 0.496 & $(0.76)$ & & \\
\hline Professional efficacy & -0.439 & -0.247 & -0.318 & -0.544 & $(0.76)$ & \\
\hline GHQ-12 & 0.621 & 0.477 & 0.526 & 0.423 & -0.336 & (0.89) \\
\hline
\end{tabular}

Table 6 Prevalence at baseline and one year cumulative incidence

\begin{tabular}{llllll}
\hline & \multicolumn{2}{c}{ Baseline } & & \multicolumn{2}{l}{ One year follow up } \\
\cline { 2 - 3 } \cline { 5 - 6 } Outcome measure & $\mathrm{n}$ & Prevalence \% & & $\mathrm{n}$ & $\begin{array}{c}\text { One year cumulative } \\
\text { incidence \% }\end{array}$ \\
\hline Prolonged fatigue & 11902 & 21.9 & 7329 & 12.0 \\
Need for recovery & 12059 & $25.0^{*}$ & 7179 & 16.9 \\
Burnout & 12053 & $13.7^{*}$ & & 8239 & 8.3 \\
Psychological distress & 12025 & 22.9 & & 7389 & 11.9 \\
\hline * Based on statistical norms. & & & & \\
\hline
\end{tabular}

prolonged fatigue as measured with the CIS was $21.9 \%{ }^{45}$ The one year cumulative incidence of prolonged fatigue was $12.0 \%$. Similar values were observed for psychological distress. For burnout, as measured with the MBI-GS, prevalence and one year cumulative incidence were lower than for prolonged fatigue.

\section{Prevalence of prolonged fatigue: differences across sectors, companies, and departments}

Table 7 shows the prevalence of prolonged fatigue across different sectors and trades classified according to The Netherlands Standard Classification of Occupations 1992. ${ }^{46}$ The prevalence varied considerably. The highest prevalence was found within the sector "agriculture, hunting, forestry, fishing" $(28.4 \%)$, while the lowest prevalence was found in the building industry (13.8\%). Table 8 presents the differences in prevalence of fatigue across different companies within the industrial sector. Noticeably, differences in prevalence of fatigue were found between $9.7 \%$ and $28.4 \%$. Similar differences were observed in the remaining sectors (specific data not shown). Table 8 also illustrates differences in prevalence across diverse departments within one company, ranging from $20.5 \%$ to $31.7 \%$. Within other companies, comparable differences across departments were found (specific data not shown).

\section{DISCUSSION}

In this paper, we describe an epidemiological approach to study prolonged fatigue in the working population and we present the main characteristics of the Maastricht Cohort

Table 7 Differences in the prevalence of prolonged fatigue across sectors and trades

\begin{tabular}{lrrl}
\hline Sector/trade & & $\begin{array}{c}\text { \% of study } \\
\text { population }\end{array}$ & $\begin{array}{l}\text { Fatigue } \\
\text { prevalence }\end{array}$ \\
\hline Agriculture, hunting, forestry, fishing & 71 & 0.6 & 28.4 \\
Industry & 5581 & 46.0 & 22.4 \\
Building industry & 209 & 1.7 & 13.8 \\
Public services & 311 & 2.6 & 20.9 \\
Culture, recreation, other services & 178 & 1.5 & 27.7 \\
Catering industry & 260 & 2.1 & 26.6 \\
Transport, storage, and communication & 772 & 6.4 & 23.9 \\
Financial institutions & 103 & 0.8 & 20.4 \\
Letting and business services & 1577 & 13.0 & 23.4 \\
Public administration, social insurance & 939 & 7.7 & 21.6 \\
Education & 315 & 2.6 & 24.8 \\
Health care and public welfare work & 1824 & 15.0 & 17.6 \\
Total study population & 12140 & 100.0 & 21.9 \\
\hline
\end{tabular}


Table 8 Differences in prevalence of prolonged fatigue across 12 companies within the industrial sector; and across departments within one specific company (A)

\begin{tabular}{|c|c|c|c|c|}
\hline Company & $\mathrm{n}$ & $\begin{array}{l}\text { Fatigue } \\
\text { prevalence \% }\end{array}$ & Department & $\begin{array}{l}\text { Fatigue } \\
\text { prevalence } \%\end{array}$ \\
\hline A & 1471 & 28.4 & $\begin{array}{r}\text { Production } \\
\text { Assembly } \\
\text { Control } \\
\text { Services } \\
\text { Engineering }\end{array}$ & $\begin{array}{l}31.7 \\
30.2 \\
20.5 \\
25.2 \\
23.2\end{array}$ \\
\hline B & 202 & 22.5 & & \\
\hline C & 983 & 16.9 & & \\
\hline D & 68 & 25.4 & & \\
\hline E & 49 & 12.2 & & \\
\hline $\mathrm{F}$ & 259 & 15.3 & & \\
\hline G & 1522 & 21.8 & & \\
\hline H & 94 & 26.9 & & \\
\hline 1 & 25 & 28.0 & & \\
\hline J & 135 & 9.7 & & \\
\hline K & 31 & 22.6 & & \\
\hline L & 742 & 23.6 & & \\
\hline Total industry & 5581 & 22.4 & & \\
\hline
\end{tabular}

Study in terms of study design, study population, and outcome measures. Our model for epidemiological research of prolonged fatigue in the working population has proved to be a useful tool for the establishment of the Maastricht Cohort Study. The prospective cohort design, in which both risk factors and outcomes are frequently measured on an individual level during a three year follow up period, enabled us to examine causal relations (including interactions) and to incorporate different causal conceptualisations (for example, exposure time effect, initial impact concept). ${ }^{47-49}$

In aetiological research the study base should contain sufficient contrast in exposure. For reasons of efficiency in most studies, the contrast is obtained through a selection and comparison of high risk groups and low risk groups. Intermediate effects, however, cannot be studied with such an approach. In the Maastricht Cohort Study, a heterogeneous population of employees from different companies and organisations with different occupations and tasks were included. As presented in this paper the study population at baseline is heterogeneous with respect to demographic variables, work characteristics, health, and social and domestic factors. Our recruitment strategy ensured contrast and allowed us to study intermediate effects. Because of the multifactorial aetiology of fatigue, we assessed exposure in terms of work related factors, domestic/social factors, and individual characteristics. In the Maastricht Cohort Study, both exposure and outcome were measured on an individual level by means of self administered questionnaires. In several papers, the shortcomings of this method are discussed..$^{235051}$ The main problem is that self rated or perceived strain may be influenced by the outcome parameter, which even in prospective studies may lead to information bias and common method variance. To overcome this problem, supplementary independent exposure and outcome measures are suggested. ${ }^{51}$ However, because of the large number of participants in our study it is impossible to obtain supplementary, independent exposure and outcome information. However, within the MCS, independent information on sick leave was obtained through record linkage with companies' sick leave registries. Within the Maastricht Cohort Study, the information bias is minimised in two ways. In aetiological research on prolonged fatigue, only healthy (non-fatigued) employees are studied, whereas in prognostic research, prevalent and incident cases (that is, fatigued employees) are used. In both situations repeated measurements of exposure and outcome during follow up minimises the information bias.
At baseline, 12140 employees participated in our study. This is a response rate of $45 \%$. A total of 9625 employees completed and returned the one year follow up questionnaire (response rate $80 \%$ ). Though reasonable for a survey in the working population, these responses raised the question of a selective participation of employees and selective drop out, which may have biased our findings. A survey among 600 non-responders at baseline indicates that the non-responders are less fatigued than the respondents. Therefore, an overestimation of the prevalence of fatigue reported in this study cannot be ruled out. A non-response analysis after one year follow up indicated that drop outs reported higher fatigue levels at baseline than respondents, which may have led to an underestimation of the cumulative one year incidence of fatigue. Another related issue concerns the composition of the study population. Although 12140 employed men and women with a large number of different occupations were included, the study population cannot be regarded as a truly representative sample of the Dutch workforce. It should be emphasised, however, that this working sample covers almost all sectors of the Dutch workforce. Moreover, it should be noted that this unique working sample provides sufficient new fatigue cases during the follow up period and made it possible to identify putative risk factors for the onset of prolonged fatigue.

Within the MCS, the main outcome is prolonged fatigue. This study shows that prolonged fatigue is continuously distributed in the working population. When using a dichotomy based on the predefined CIS cut off point $(>76)$ the prevalence is $21.9 \%$, which shows that prolonged fatigue is common in the working population. The substantial differences in the prevalence of prolonged fatigue across sectors and trades, companies, and departments lend weight to the argument that the work environment plays a role in the aetiology and natural course of fatigue. Within the MCS, a research project has prospectively shown the role of several work characteristics in the onset of fatigue. ${ }^{48}$ The one year cumulative incidence of prolonged fatigue was found to be $12.0 \%$. Hence, prevalence and incidence indicate a mean duration of prolonged fatigue of approximately 22 months, which underlines the magnitude and impact of fatigue in the working population.

However, it has to be carefully considered that the prevalence and incidence of prolonged fatigue depend on the study population, the response rate, and the predefined CIS cut off point. Admittedly, the use of a cut off point for fatigue, while rather continuously distributed, is a troublesome issue. In this paper, as well as in all other projects within the MCS, the same clear predefined cut off is used. This cut off point for prolonged fatigue was determined by means of defined samples with differences in fatigue level in a separate pilot study. ${ }^{38}$

In line with findings of earlier fatigue studies conducted across different populations, prolonged fatigue was shown to be fairly well associated with psychological distress. In spite of the observed correlation, the results of a MCS research project show that risk factors for fatigue and psychological distress are partly different and that fatigue cases and psychological distress cases only partly overlap. These findings do suggest that fatigue and psychological distress may be separate concepts. $^{45}$

The results of this paper show that fatigue is also fairly well associated with the concepts need for recovery and burnout. The prevalence and incidence of these two secondary outcome measures indicate that need for recovery has a shorter duration than prolonged fatigue, while the duration of burnout and prolonged fatigue are similar. Moreover, moderate intercorrelations exist between psychological distress, need for recovery, and burnout. Further research is needed to disentangle these concepts.

For a greater understanding of prolonged fatigue in the working population, future studies should further disentangle 
the multifactorial etiology of fatigue, examine more specifically the time course of cause and effect, and pay special attention to the temporal relation between fatigue and secondary health outcomes during follow up. These aspects will be addressed in future research within the framework of the Maastricht Cohort Study.

\section{Authors' affiliations}

IJ Kant, U Bültmann, A J H M Beurskens, L G P M van Amelsvoort, G M H Swaen, Department of Epidemiology, Maastricht University, Maastricht, Netherlands

K A P Schröer, Department of Medical Sociology, Maastricht University, Maastricht, Netherlands

\section{REFERENCES}

1 Mounstephen A, Sharpe M. Chronic fatigue syndrome and occupational health. Occup Med Oxf 1997;47:217-27

2 Meijman T, Schaufeli W. Psychische vermoeidheid en arbeid. Ontwikkelingen in de A\&O-psychologie [Fatigue at work. Developments in I\&O psychology]. De Psycholoog 1996;June:236-41.

3 Schröer CAP. De toename van arbeidsongeschiktheid wegens psychische aandoeningen [The increase of work disability due to mental disorders]. TBV 1997; 5: 16-23.

4 Houtman ILD. Trends in arbeid en gezondheid 1996 [Trends in work and health 1996]. Amsterdam: NIA/TNO, 1997.

5 Lewis G, Wessely S. The epidemiology of fatigue: more questions than answers. J Epidemiol Community Health 1992;46:92-7.

6 Barofsky I, Legro MW. Definition and measurement of fatigue. Rev Infect Dis 1991;13(suppl 1):S94-7.

7 Chalder T, Berelowitz G, Pawlikowska T, et al. Development of a fatigue scale. J Psychosom Res 1993;37:147-53.

8 Taylor RR, Jason LA, Torres A. Fatigue rating scales: an empirical comparison. Psychol Med 2000;30:849-56.

9 Chen MK. The epidemiology of self-perceived fatigue among adults. Prev Med 1986;15:74-81

10 David A, Pelosi A, McDonald E, et al. Tired, weak, or in need of rest: fatigue among general practice attenders. BM 1990;301:1199-202.

11 Cathebras PJ, Robbins JM, Kirmayer L, et al. Fatigue in primary care: prevalence, psychiatric comorbidity, illness behavior, and outcome. J Gen Intern Med 1992;7:276-86.

12 Pawlikowska T, Chalder T, Hirsch SR, et al. Population based study of fatigue and psychological distress. BMW 1994;308:763-6.

13 Fuhrer R, Wessely S. The epidemiology of fatigue and depression: a French primary-care study. Psychol Med 1995;25:895-905

14 Hickie IB, Hooker AW, Hadzi Pavlovic D, et al. Fatigue in selected primary care settings: sociodemographic and psychiatric correlates. Med J Aust 1996; 164:585-8.

15 Loge JH, Ekeberg O, Kaasa S. Fatigue in the general Norwegian population: normative data and associations. J Psychosom Res 1998:45:53-65.

16 Meijman TF. Over vermoeidheid: arbeidspsychologische studies naa beleving van belastingseffecten [Fatigue: studies on the perception of workload effects]. Amsterdam: University of Amsterdam, 1991

17 Hardy GE, Shapiro DA, Borrill CS. Fatigue in the workforce of National Health Service Trusts: levels of symptomatology and links with minor psychiatric disorder, demographic, occupational and work role factors. J Psychosom Res 1997;43:83-92.

18 Kroenke K, Wood DR, Mangelsdorff AD, et al. Chronic fatigue in primary care. Prevalence, patient characteristics, and outcome. JAMA 1988;260:929-34.

19 Schröer CAP. Verzuim wegens overspanning; een onderzoek naar de aard van overspanning, de hulpverlening en het verzuimbeloop [Sickness absense because of overstrain]. Maastricht: Maastricht University, 1993.

20 Kristal Boneh E, Froom P, Harari G, et al. Fatigue among Israeli industrial employees. J Occup Environ Med 1996;38: 1 145-50.

21 Goedkoop J, Londen van L. Relaties tussen depressie en persoonlijkheid [Relations between depression and personality]. Ned Tijdschr Geneeskd 1995; 139:165-7.

22 Parkes KR. Personality and coping as moderators of work stress processes: models, methods and measures. Work and Stress 1994;8:110-29.

23 Kristensen TS. The demand-control-support model: methodological challenges for future research. Stress Medicine 1995;11:17-26.

24 Karasek R, Brisson C, Kawakami N, et al. The Job Content Questionnaire (JCQ): an instrument for internationally comparative assessments of psychosocial job characteristics. J Occup Health Psychol 1998;3:322-55.
25 Kasl SV. Measuring job stressors and studying the health impact of the work environment: an epidemiolgic commentary. J Occup Health Psychol 1998;3:390-401

26 Rothman KJ, Greenland S. Modern epidemiology, 2nd edn. Philadelphia: Lippencott-Raven, 1998.

27 Frese M, Zapf D. Methodological issues in the study of work stress: objective vs subjective measurement of work stress and the question of longitudinal studies. In: Cooper CL, Payne R, eds. Causes, coping, and consequences of stress at work. Chichester: Wiley, 1988:375-411.

28 Zapf D, Dormann C, Frese M. Longitudinal studies in organizational stress research: a review of the literature with reference to methodological issues. J Occup Health Psychol 1996;1:145-69.

29 Nicholson N. A theory of work role transitions. Adm S Quart 1984;29:172-91.

30 Hickie I, Koschera A, Hadzi-Pavlovic D, et al. The temporal stability and co-morbidity of prolonged fatigue: a longitudinal study in primary care. Psychol Med 1999;29:855-61

31 Van der Linden G, Chalder T, Hickie I, et al. Fatigue and psychiatric disorder: different or the same? Psychol Med 1999;29:863-8.

32 Koschera A, Hickie I, Hadzi-Pavlovic D, et al. Prolonged fatigue, anxiety and depression: exploring relationships in a primary care sample. Aust N Z J Psychiatry 1999;33:545-52.

33 Maslach C, Jackson SE. Maslach Burnout Inventory manual, 2nd edn. Palo Alto, CA: Consulting Psychologists Press, 1986.

34 Vercoulen JH, Swanink CM, Fennis JF, et al. Dimensional assessment of chronic fatigue syndrome. J Psychosom Res 1994;38:383-92.

35 Vercoulen JH, Hommes OR, Swanink CM, et al. The measurement of fatigue in patients with multiple sclerosis. A multidimensional comparison with patients with chronic fatigue syndrome and healthy subjects. Arch Neurol 1996;53:642-9

36 Vercoulen JH, Swanink CM, Fennis JF, et al. Prognosis in chronic fatigue syndrome: a prospective study on the natural course. J Neurol Neurosurg Psychiatry 1996;60:489-94

37 Beurskens AJHM, Bultmann U, Kant I, et al. Fatigue among working people: validity of a questionnaire measure. Occup Environ Med 2000:57:353-7.

38 Bültmann U, De Vries M, Beurskens AJHM, et al. Measurement of prolonged fatigue in the working population: determination of a cutoff point for the Checklist Individual Strength. J Occup Health Psychol 2000;5:411-16.

39 Goldberg D. Epidemiology of mental disorders in primary care settings. Epidemiol Rev 1995;17:182-90.

40 Koeter MWJ, Ormel J. General Health Questionnaire, Handleiding Nederlandse bewerking [General Health Questionnaire, Manual Dutch version]. Lisse: Swets \& Zeitlinger, 1991.

41 Wall TD, Bolden RI, Borrill CS, et al. Minor psychiatric disorder in NHS trust staff: occupational and gender differences. Br J Psychiatry 1997:171:519-23.

42 Van Veldhoven M, Meijman T. Het meten van psychosociale arbeidsbelasting met een vragenlijst: De Vragenlijst Beleving en Beoordeling van de Arbeid (VBBA) [Questionnaire on Perception and Judgement of Work]. Amsterdam: NIA, 1994.

43 Sluiter JK, van der Beek AJ, Frings Dresen MH. The influence of work characteristics on the need for recovery and experienced health: a study on coach drivers. Ergonomics 1999;42:573-83.

44 Schaufeli WB, Van Dierendonk D. UBOS, Utrechtse Burnout Schaal, Handleiding. Lisse: Swets Test Publishers, 2000.

45 Bültmann U, Kant I, Kasl S, et al. Fatigue and psychological distress in the working population: psychometrics, prevalence, and correlates. J Psychosom Res 2002:52:445-52.

46 CBS. Standaard Beroepenclassificatie 1992 [The Netherlands Standard Classification of Occupations 1992]. 's-Gravenhage: SDU/uitgeverii, 1993.

47 Swaen G, Kant I, Amelsvoort van L, et al. Job mobility, its determinants, and its effects: longitudinal data from the Maastricht Cohort Study. J Occup Health Psychol 2002;7:121-9.

48 Bültmann U, Kant I, Brandt van den P, et al. Psychosocial work characteristics as risk factors for the onset of fatigue and psychological distress: prospective results from the Maastricht Cohort Study. Psychol Med 2002;32:333-45

49 Bültmann U, Kant I, Kasl S, et al. Lifestyle factors as risk factors for fatigue and psychological distress in the working population: prospective results from the Maastricht Cohort Study. J Occup Environ Med 2002;44:116-24.

$50 \mathrm{Kasl}$ SV. The influence of the work environment on cardiovascular health: a historical, conceptual, and methodological perspective. J Occup Health Psychol 1996;1:42-56.

51 Kristensen TS. Job stress and cardiovascular disease: a theoretic critical review. J Occup Health Psychol 1996;1:246-60 